\title{
High-risk HPV test in cervical cancer prevention - present and future
}

\author{
Natalia Zarankiewicz ${ }^{1, A-D \oplus}$, Martyna Zielińska ${ }^{1, B-C \oplus}$, Katarzyna Kosz $^{1, B-C \oplus}$,

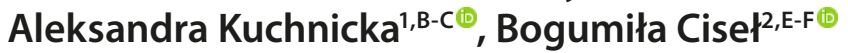 \\ 1 Student's Scientific Association, Oncological Surgery Department, Medical University, Lublin, Poland \\ 2 Oncological Surgery Department, Independent Public Teaching Hospital No.,1 in Lublin; Medical University, Lublin, \\ Poland \\ A - Research concept and design, B - Collection and/or assembly of data, C - Data analysis and interpretation, \\ $D$ - Writing the article, $E$ - Critical revision of the article, $F$ - Final approval of article
}

Zarankiewicz N, Zielińska M, Kosz K, Kuchnicka A, Ciseł B. High-risk HPV test in cervical cancer prevention - present and future. J Pre Clin Clin Res. 2020; 14(3): 80-84. doi: 10.26444/jpccr/126432

\begin{abstract}
Introduction. Cervical cancer is the fourth most common cancer among women. It is related to persistent HPV infection. In order to improve diagnostic methods, a lot of research has been focused on detecting HPV DNA. A test known as a highrisk HPV test or HPV primary screening provides very encouraging results.

Objective.The aim of this review is to present the actual knowledge about the possibilities of cervical cancer screening methods. Particular attention is paid to the question concerning the effectiveness of detecting viral DNA as a screening programme, compared to pap smear.

State of knowledge. The HPV primary screening has higher sensitivity than the cervical smear test and it is able to detect lower-stage lesions, which are considered clinically irrelevant. Nonetheless, many HPV infections recede naturally. Therefore, relying only on the results of this test may expose women to unnecessary colposcopies and stress. Due to this fact, women under 30 years should not be screened with the hrHPV test. In view of its limitations, the HPV primary screening strategy is still tested worldwide as a pilot project. In Poland in 2019, a pilot project with the hrHPV test started at the National Institute of Oncology.

Conclusions. Detecting viral DNA has its advantages and disadvantages. Further research is still required, but the hrHPV test has a great opportunity to become one of the main screening programmes worldwide, or at least, a valuable addition to cervical smear test.
\end{abstract}

\section{Key words}

cervical cancer, cervical screening, HPV primmary screening, hrHPV test, HPV DNA

\section{- Abbreviations}

HPV - human papillomavirus; DNA - Deoxyribonucleic acid; hrHPV test- high-risk HPV test; WHO - World Health Organization; CIN3 - cervical intraepithelial neoplasia, grade 3; USPSTF - The US Preventive Services Task Force; CIN2 cervical intraepithelial neoplasia, grade 2; CIN2+-cervical intraepithelial neoplasia, grade 2 or worse, including CIN3; LBC - liquid-based cytology; CIN3+ - CIN3 or worse, including invasive cervical cancer; FDA - Food and Drug Administration; ATHENA - Addressing the Need for Advanced HPV Diagnostics; ASC-US - Atypical Squamous Cells of Undetermined Significance; NILM - Negative for Intraepithelial Lesion or Malignancy

\section{INTRODUCTION AND OBJECTIVE}

The human papillomavirus belongs to the Papillomaviridae family which infects human epithelial tissue, and is able to affect the skin, oral and genital mucosa [1]. According to current knowledge, probably about $20-25 \%$ of all cancers may be related to microorganism infections. HPV is considered to be responsible for $30 \%$ of all infectious-related malignancies, including cervical, vulvar, vaginal, penile, anal cancer, head and neck squamous cell carcinoma, oesophageal carcinoma, ophthalmic carcinoma, and probably breast cancer [2]. Cervical cancer affects adult women, mostly between the ages of $35-50$. Worldwide mortality from this neoplasm is decreasing, a phenomenon which can be explained by the increasingly developing screening methods. The most

Address for correspondence: Natalia Zarankiewicz, Students' Scientific Association, Oncological Surgery Department, Medical University, Lublin, Poland E-mail: natalia.zarankiewicz@gmail.com

Received: 11.04.2020; accepted: 17.08.2020; first published: 03.09.2020 well-known screening test which is a cornerstone of cervical prevention is a cervical smear. Although there are also some new methods which definitely should be taken into consideration [3], one of the rapidly developing methods is HPV primary screening for detecting viral nucleic acids [4]. According to many studies, new technologies detect more lesions than the standard cervical smear test. However, there are also some evident disadvantages because many lesions undergo spontaneous regression and their identification may lead to unnecessary fear and treatment [3].

Several countries have adopted the hrHPV test for their screening programmes. The National Institute of Oncology in Poland announced that they started the Pilot Molecular hrHPV Test in the third quarter of 2019. It is dedicated to women aged between 30 - 59 who have not participated in the National Prevention Programme based on the pap smear test in the last three years [5].

The aim of this review is to present actual knowledge of cervical cancer screening methods, and current data about 
detecting viral DNA. HPV primary screening may become an effective alternative for Pap test or even replace this test in the future.

The review was prepared using books and Internet resources. When preparing the study, the analysis concerned articles published between 2010 - 2020 which included terms such as: cervical cancer, HPV primary screening, hrHPV test, cervical screening, HPV DNA. All the studies were collected from the PubMed, Google Scholar and World Health Organization websites.

Cervical cancer biology. According to the WHO, cervical cancer is the fourth most common cancer in women. It is estimated that HPV caused 528,000 new cases of cervical cancer and 266,000 deaths in 2012 [6]. Approximately 85\% of deaths caused by HPV take place in low- and middleincome countries [2].

It is proven that the persistent HPV infection is necessary for the development of high-grade cervical neoplasia, determined as a CIN3 [7]. There are several viral genotypes identified which are related to malignancies (e.g. HPV 16, $18,31,33,35,39,45,51,52,56,58$ and 59). HPV infection begins with viral access to basal keratinocytes of skin and mucosa. The next step is a conformational change in viral capsid and viral internalization in a vacuolar structure that integrates with lysosomes. Decrease in $\mathrm{pH}$ leads to viral genome release [2]. Although the HPV does not express its own polymerases, the replication process is possible with the use of host cell DNA polymerase. This process is initiated with the oncoproteins activity (E5, E6 and E7) which may lead to disorders of DNA replication and chromosome instability. This step is considered as a cancer initiation [8]. In addition to genomic instability, some metabolic deregulations are also necessary to promote carcinogenesis. This requirement was described by Francis Peyton Rous in one famous sentence, as 'a process in which tumour goes from bad to worse'. This means that chromosomal instability is necessary, but insufficient to promote carcinogenesis.

Cancer cells have developed anti-apoptotic strategies to avoid cell death, one of which is down-regulation of the TP53, called the Guardian of the Genome [2,9]. Another strategy is gaining the human telomerase gene due to viral integration within promoter region $5 q 15$ or next to $3 q 26$. This action enables the multiplication of sub-clones and thereby cancer development progresses [10].

Primary and secondary prevention of cervical cancer. It has been estimated that it will take in excess of seven years to develop cervical intraepithelial neoplasia after DNA incorporation into the host cell genome. The next three to five years are necessary for full cervical cancer expansion [11]. The multiannual progression creates a great possibility for early detection of harmless lesions. In recent times, screening programmes have been based on three procedures: the cervical smear test, HPV primary screening (also known as a high-risk HPV testing), and hybrid strategy, the cervical smear test combined with the hrHPV test $[4,12]$.

Besides the screening programmes, there is also the possibility of primary prevention of cervical cancer by applying HPV vaccinations. The USPSTF guidelines recommends a 2-dose schedule for both genders, initiating vaccination between the ages of 9-14 and 3 doses for teenagers and young adults aged 15-26. Prophylactic vaccinations may decrease the number of cervical cancer cases in the future, although there is still a great necessity for the continuation of cervical screening, including the population of HPVvaccinated women [12]. This is related to the lack of knowledge about the long-term efficacy of the vaccines, and scientists admit that HPV types which are not targeted in current vaccines may also have oncogenic potential [3].

A population-based study described by Baldur-Felskov et al. compared vaccinated and unvaccinated Danish women in terms of risk for cervical precursor lesions. The authors reported that vaccinated women had a statistically significantly reduced risk of CIN2 and CIN3 [13]. The Australian Compass pilot randomised trial assessed 4,995 participants chosen from an initial group of 5,303 women, some of whom had previously been offered HPV vaccinations. The criterion for being classified as age-eligible for vaccination was the age of 33 years or younger in 2014. After adjusting for HPV vaccination age eligibility, the study showed that the hrHPV test was associated with a significantly higher detection rate of CIN2+ than LBC. The overall CIN2+ rates were as follows: $0.1 \%$ in women tested with LBC versus $1.0 \%$ and $1.2 \%$ in two groups screened with the hrHPV test $(p=0.003)$ [14]. This finding has become a point of origin for the main randomised Compass trial in Australia. The trial is aimed at comparing primary HPV testing with pap smear screening for cervical cancer in HPV-unvaccinated and HPV-vaccinated Australian women aged 25-69 years. A total of 121,000 participants are planned to be recruited. The study started in January 2015 and the estimated study completion date is December 2023. Participants will be observed for five years from the time of recruitment, and the primary outcome will be based on the total CIN3+ detection rates in the LBC and the hrHPVtested groups [15].

The effectiveness of HPV primary screening in clinical trials. There are five HPV DNA tests approved by the FDA: Hybrid Capture 2, Cervista HPV HR and Cervista HPV 16/18, Cobas and Onclarity. All these tests are able to detect twelve HPV types with the highest carcinogenic potential [16]. The examined material is a pap smear taken with a dedicated brush. The usefulness of self-collected samples is still under discussion [17].

A number of prospective clinical trials have evaluated the performance of HPV primary screening programmes in different parts of the world. The first adduced research is a prospective study initiated in the USA by the ATHENA study group in 2008. The cervical samples were tested using the Cobas HPV Test. The results provide three positive/negative results: HPV16, HPV18 and 12 other genotypes (31, 33, 35, $39,45,51,52,56,58,59,66$ and 66 , pooled).

From the initial group of 42,209 women, 40,901 participated in the research, divided into three groups. The first strategy was pap smear and hrHPV test for women with ASC-US in a previous pap smear. The second was the so-called hybrid strategy, which means pap smear for women aged between $25-29$, and both the hrHPV test and pap smear after the age of 30 . The latter was an HPV primary screening strategy with rescreening HPV-negative women in three years, and colposcopy for HPV 16/18-positive women. Women infected with twelve other HPV genotypes had reflex cervical smear test and colposcopy, depending on the result of the cervical smear test. If the pap smear was negative, the women were rescreened with hrHPV and pap smear in one year. 
In women over the age of 25 , sensitivity in $\mathrm{CIN} 3+$ detection was as follows: $76.1 \%(95 \% \mathrm{CI}$; 70.3-81.8\%) for HPV primary screening, 61.7\% (95\% CI; 56.0-67.5\%) for hybrid strategy and 47.8\% (95\% CI; 41.6-54\%) for pap smear test. Nevertheless, the specificity for pap smear was $97.1 \%$ (95\% CI; 96.9-97.2\%), and only $93.5 \%$ (95\% CI; 93.3-93.8\%) for the HPV primary screening. In women over the age of 30 , pap smear also had the highest specificity. The sensitivity was higher and at a similar level for both methods, the HPV primary screening and the hybrid strategy [4]. It should be pointed out that the traceability and decrease in the incidence of CIN3 can be considered only as a surrogate measure for the effectiveness of screening programmes. The most reliable indicator is a reduction in the cancer morbidity and mortality [3].

A prospective randomized controlled trial with primary HPV testing was performed in a Chinese population between May 2010 and April 2014, which consisted of two rounds of cervical screening. From the initial group of 15,955 women between the ages of $30-60,15,858$ were finally considered to be eligible to participate in the study. They were divided into two groups based on screening methods. Women in the control group were tested only with LBC. The interventional group underwent co-testing with the use of LBC and Hybrid Capture $2 \mathrm{hrHPV}$ test. This test detects a pool of 13 high-risk HPV types (16, 18, 31, 33, 35, 39, 45, 51, 52, 56, 58, 59 and 68). Women tested negative in baseline screening were given a subsequent Liquid-based screening alone 36 months later.

Despite the fact that in baseline screening 15,431 (97,3\%) women had negative pap smear results, $7.3 \%$ of them tested positive for hrHPV genotypes. Moreover, CIN2+ and CIN3+ detection was significantly higher in the intervention group in baseline screening. There were 75 and 30 women with CIN2+ lesions in the co-tested and control groups, respectively $(\mathrm{OR}=2.50,95 \% \mathrm{CI} ; 1.65-3.88 ; \mathrm{p}<0.001)$. In these groups, the number of women with CIN3+ lesions was 49 and 16 , respectively $(\mathrm{OR}=3.06,95 \% \mathrm{CI}: 1.78-5.58 ; \mathrm{p}<0.001)$. In the subsequent round, the detection rate of CIN2+ and CIN3+ lesions was significantly lower in those who had previously received co-testing. There were three cervical cancers detected in baseline screening, and not a single one in subsequent screening [18].

The next important study was a population-based cohort study conducted in The Netherlands. In 2017, Dutch screening policy changed the pap smear-based programme to hrHPV testing. The study compared the results of cervical smear screening before 2017 with the results of using hrHPV test. It is important to note that in The Netherlands cervical smear test can be taken with a self-sampling kit or collected by a healthcare professional. Detection rate of the hrHPV genotypes was lower in self-collected samples than in samples collected by professionals $(7.6 \%$ vs $9,2 \%$; $<<0.001)$. The proportion of women tested positive increased significantly from $5 \%$ in 2015 to $9 \%$ in 2017, when HPV primary screening was implemented $(\mathrm{p}<0.001)$. An increase was also noted in the proportion of women referred to gynaecologists $(1 \%$ in the programme based on pap smear test and 3\% in the programme based on the hrHPV test; $\mathrm{p}<0.001)$. The overall CIN2+ detection rate increased from 11/1,000 women in the pap smear-based programme up to $14 / 1,000$ women in the hrHPV-based programme $(\mathrm{p}<0.001)$. The authors pointed out that about 2.2 times more clinically irrelevant and 1.3 times more clinically relevant findings were found in the hrHPV-based programme [19].
A population-based cervical cancer screening programme using HPV testing was carried out in Turkey. Authors evaluated the initial results of the first million women screening with Hybrid Capture 2 HPV test after its official implementation in 2014. The total number of women included in the research was $1,060,992$, of whom $3.5 \%$ proved to be HPV positive. Further procedures depended on pap smear results. Women with oncogenic HPV genotypes (16 or 18) or HPV positive with lesions qualified as ASC-US or worse in pap smear, were referred to colposcopy. Finally, 3,499 women underwent colposcopy with or without diagnostic procedures (e.g. conization). CIN2 lesions were detected in 285 cases and CIN3 in 436 cases, while cervical cancer was detected in 85 cases. Among them, 54 were invasive. Altogether, there were 521 samples with more invasive lesions than CIN3. In the cervical smear test, after excluding 58 samples described as 'insufficient', 188 of the 521 samples were considered to be 'infected without malignancy', and 24 results were described as NILM. This indicates that the cervical smear test could miss approximately $46 \%$ of higher-stage lesions than CIN3 [20].

HPV primary as a new screening programme. As mentioned above, the hrHPV test has higher sensitivity than pap smear in CIN3 detection, and it also enables detecting of lower-stage lesions. As for disadvantages, the hrHPV test features lower specificity and lower positive predictive value, especially in younger women $[4,21]$. The high sensitivity is connected with high negative predictive values, and according to current knowledge, this value may be valid up to ten years, even for adenocarcinoma precursors [3]. This indicates that the use of the HPV primary as a screening programme may reduce the costs and the complexity of national screening programmes [4].

Nowadays, the number of women infected with HPV is enormous. The majority of over-diagnosed lesions would spontaneously regress without clinical consequences. For this reason, women under the age of 30 should not be screened with the hrHPV test. High test sensitivity is related to both harm and benefit. Detection of lower-stage lesions is connected with the risk of unnecessary stress and colposcopies. Analysis of the results of both screening programmes in the Netherlands pointed out that - in comparison with pap smear - the hrHPV test detects roughly 2.2 times more lower-stage lesions (CIN1 or even lesions without dysplasia). Lesions in a lower stage than CIN2 are considered to be clinically insignificant [16]. Furthermore, in the mentioned randomized trial in a Chinese population, the number of performed colposcopies was higher in women co-tested with the hrHPV screening than in the control group $(9.3 \%$ vs $2.0 \%$; $<0.001)$. Finally, it was alleged that in the control group there were 6.4 colposcopies needed for one CIN2+ detection and 11.3 colposcopies in the intervention group [18]. In addition, some studies indicate that women with HPV-positive test who have undergone colposcopy, complain about negative feelings about their sexuality $[3,22]$. That is why there is a necessity to develop a strategy of selecting women who should undergo a colposcopy [4].

Many countries conduct pilot projects with the HPV primary as a screening programme, and several have already included the HPV DNA test in their national screening programmes. In the USA, due to USPSTF guidelines, for women aged 21-29, it is suggested that they should undergo a 
cervical smear test every three years. Co-testing with cervical smear and the hrHPV test is recommended in women aged $30-65$, at five year intervals $[12,23,24]$. As mentioned, in The Netherlands, the screening policy was changed in 2017. Additionally, Dutch women can choose between selfsampling and clinical procedure of taking a smear. The main assumption of the Dutch screening programme is that women between the ages of 30 and 60 undergo the hrHPV test at five years intervals. Nevertheless, there are several exceptions; women with negative test results at the age of 40 or 50 are invited for the next screening in ten years time. In the case of a positive test result at the age of 60 , women are tested additionally once again at the age of $65[4,18]$. In Germany, the screening policy is also changing; previous screening policy was based on cervical smear testing every year. Recently, in women aged $20-34$ it is still suggested that they undergo annual cervical smear screening. However, from the age of 35, women are co-tested with hrHPV every three years [25].

Cervical cancer and screening programme in Poland. In 2017 in Poland, cervical cancer was considered the seventh most common female malignancy and the eighth leading cause of death - the second most common malignancy in women at the age group $20-44$. According to the CONCORD-3 programme, the 5 -year survival rate for women with cervical cancer in Poland is still the worst among the European countries included in the research [26]. These unsatisfactory results may be explained by the low effectiveness of screening tests, diagnosing women with high-stage cancers, or the low quality of available treatment [27].

Cervical screening policy in Poland is based on the pap smear test. The National Prevention Programme offers pap smear every three years for women aged $25-59$, or every year for those who are burdened with risk factors (women with HIV or hrHPV infections or taking immunosuppressants) [28]. Research by Jankowska et al. in 2017 reported that as many as $39 \%$ of respondents had never undergone cervical screening. Less than half (42\%) had been screened with pap smear in the last three years [29].

The National Institute of Oncology in Poland started the Pilot Molecular hrHPV Test on 28th October, 2019. This programme is dedicated to women aged between $30-59$ who have not participated in the National Prevention Programme in the last three years. The purpose of the pilot study is to compare the effectiveness of pap smear test and the hrHPV test [5].

\section{CONCLUSIONS}

In the light of the high incidence of cervical cancer worldwide, there is a great demand for even more efficient screening methods. Detecting viral DNA, known as the hrHPV test, is one of the most popular technologies today. This test has high sensitivity, but also lower specificity than pap smear. In order to provide a well-functioning cervical screening based on the hrHPV test, an improved strategy for colposcopy referral must be implemented. Therefore, there is a requirement for further studies to develop the ideal screening method. Early detection of precancerous lesions plays the major role in protection of women's health. Besides, introduction of the hrHPV test may reduce the expenses of national screening programmes inter alia through the prolongation of the periods between subsequent examinations. This illustrates that the development of this field of diagnostics is very important for modern women worldwide.

\section{REFERENCES}

1. Tomassino M. The human papillomavirus family and its role in carcinogenesis. Seminars in Cancer Biology. 2014; 26: 13-21. doi: 10.1016/j.semcancer.2013.11.002

2. Araldi RP, Sant'Ana TA, Módolo DG, de Melo TC, Spadacci-Morena DD, de Cassia Stocco R, et al. The human papillomavirus (HPV)related cancer biology: An overview. Biomed Pharmacother. 2018; 106 1537-1556. doi: 10.1016/j.biopha.2018.06.149

3. Arbyn M, Antilla A, Jordan J, Ronco G, Schenck U, Segnan N, et al. European Guidelines for Quality Assurance in Cervical Cancer Screening. Second Edition-Summary Document. Ann Oncol. 2010 21(3): 448-458. doi: 10.1093/annonc/mdp471

4. Wright TC, Stoler MH, Behrens CM, Sharma A, Zhang G, Wright TL. Primary cervical cancer screening with human papillomavirus: End of study results from the ATHENA study using HPV as the first-line screening test. Gynecol Oncol. 2015; 136(2): 189-197. doi: 10.1016/j. ygyno.2014.11.076

5. Centrum Onkologii - Instytut im. Marii Curie-Skłodowskiej. Pilotaż HPV. https://www.coi.pl/profilaktyka-i-badania-przesiewowe/ poradnia-profilaktyki-raka-szyjki-macicy/pilotazu-zastosowaniabadania-molekularnego-w-kierunku-wirusa-brodawczaka-ludzkiegowysokiego-ryzyka-hpv-hr-jako-nowego-testu-przesiewowego-w-programie-profilaktyki-raka-szyjki-macicy-w-polsce/ (access: 30.12.2019; 03.08.2020)

6. World Health Organization. Human papillomavirus (HPV). wht.int/ immunization/diseases/hpv/en (access: 30.12.2019)

7. Rositch AF, Koshiol J, Hudgens M, Razzaghi H, Backes DM, Pimenta JM, et al. Patterns of persistent genital human papillomavirus infection among women worldwide: a literature review and meta-analysis. Int Cancer. 2013; 133(6): 1271-1285. doi: 10.1002/ijc.27828

8. Araldi RP, Assaf SMR, de Carvalho RF, Carvalho MACR, Souza JM, Magnelli RF, et al. Papillomaviruses: a systematic review. Genet $\mathrm{Mol}$ Biol. 2017; 40(1): 1-21. doi: 10.1590/1678-4685-GMB-2016-0128

9. Toufektchan E, Toledo F. The Guardian of the Genome Revisited: p53 Downregulates Genes Required for Telomere Maintenance, DNA Repair, and Centromere Structure. Cancers (Basel) 2018; 10(5): 135 doi: $10.3390 /$ cancers 10050135

10. Hu Z, Zhu D, Wang W, Li W, Jia W, Zeng X, et al. Genome-wide profiling of HPV integration in cervical cancer identifies clustered genomic hot spots and a potential microhomology-mediated integration mechanism. Nat Genet. 2015; 47(2): 158-163. doi: 10.1038/ng.3178

11. Nowak-Markwitz E. Onkologia Ginekologiczna. In: Bręborowicz GH. Położnictwo i ginekologia. Vol.2. Ed. 2, Warsaw; 2015. p. 197.

12. Sawaya GF, Smith-McCune K, Kuppermann M. Cervical Cancer Screening. More Choices in 2019. JAMA 2019; 321(20): 2018-2019. doi: 10.1001/jama.2019.4595

13. Baldur-Felskov B, Dehlendorff C, Munk C, Kjaer SK. Early impact of human papillomavirus vaccination on cervical neoplasia--nationwide follow-up of young Danish women. J Natl Cancer Inst. 2014; 106(3) djt460. doi: 10.1093/jnci/djt460

14. Canfell K, Caruana M, Gebski V, Darlington-Brown J, Heley S, Brotherton J, et al. Cervical screening with primary HPV testing or cytology in a population of women in which those aged 33 years or younger had previously been offered HPV vaccination: Results of the Compass pilot randomised trial. PLoS Med. 2017; 14(9): e1002388. doi: 10.1371/journal.pmed.1002388

15.https://clinicaltrials.gov/ct2/show/NCT02328872?term=NCT02328 $872 \&$ cond $=$ Cervical + Cancer $\&$ cntry $=A U \& d r a w=2 \& \operatorname{rank}=1$ (access 04.08.2020)

16. Demarco M, Carter-Pokras O, Hyun N, Castle PE, He X, Dallal CM, et al. Validation of a Human Papillomavirus (HPV) DNA Cervical Screening Test That Provides Expanded HPV Typing. J Clin Microbiol. 2018; 56(5): 01910-17. doi: 10.1128/JCM.01910-17

17. Bansil P, Wittet S, Lim JL, Winkler JL, Paul P, Jeronimo J. Acceptability of self-collection sampling for HPV-DNA testing in low-resource settings: a mixed methods approach. BMC Public Health 2014; 14:596. doi: 10.1186/1471-2458-14-596

18. Chan KKL, Liu SS, Wei N, Ngu SF, Chu MMY, Tse KY, et al. Primary HPV testing with cytology versus cytology alone in cervical screening-A 
prospective randomized controlled trial with two rounds of screening in a Chinese population. Int J Cancer. 2020 Jan 10. doi: 10.1002/ijc.32861

19. Aitken CA, van Agt HME, Siebers AG, van Kemenade FJ, Niesters HGM, Melchers WJG, et al. Introduction of primary screening using high-risk HPV DNA detection in the Dutch cervical cancer screening programme: a population-based cohort study. BMC Med. 2019; 17(1): 228. doi: 10.1186/s12916-019-1460-0

20. Gultekin M, Zayifoglu Karaca M, Kucukyildiz I, Dundar S, Boztas G, Semra Turan H, et al. Initial results of population based cervical cancer screening program using HPV testing in one million Turkish women. Int J Cancer. 2018; 142(9): 1952-1958. doi: 10.1002/ijc.31212

21. Mariani L, Igidbashian S, Sandri MT, Vici P, Landoni F. The clinical implementation of primary HPV screening. Int J Gynaecol Obstet. 2017; 136(3): 266-271. doi: 10.1002/ijgo.12065

22. Curry SJ, Krist AH, Owens DK, Barry MJ, Caughey AB, Davidson KW, et al. (US Preventive Services Task Force). Screening for Cervical Cancer: US Preventive Services Task Force Recommendation Statement. JAMA. 2018; 320(7): 674-686. doi: 10.1001/jama.2018.10897

23. Sawaya GF, Sanstead E, Alarid-Escudero F, Smith-McCune K, Gregorich SE, Silverberg MJ, et al. Estimated Quality of Life and Economic
Outcomes Associated With 12 Cervical Cancer Screening Strategies: A Cost-effectiveness Analysis. JAMA Intern Med. 2019; 179(7): 867-878. doi: 10.1001/jamainternmed.2019.0299

24. https://www.americashealthrankings.org/explore/health-of-womenand-children/measure/cervical_cancer_screen_women/state/ALL (access: 10.05.2020)

25. Sroczynski G, Hillemans P, Siebert U. New cervical cancer policy in Germany- what is the impact on the benefit-harm balance? Value in Health. 2019; 22(3): 443. doi: 10.1016/j.jval.2019.09.240

26. Didkowska J, Wojciechowska U, Czaderny K, Olasek P, Ciuba A. Cancer in Poland in 2017. Polish National Cancer Registry 2019; Department of Epidemiology and Cancer Prevention, p. 1-30.

27. Nowakowski AM, Kotarski J. Cervical cancer in Poland and in the world - in the light of incidence and mortality data. Przegl Epidemiol. 2011; 65: 75-79.

28. www.gov.pl/web/zdrowie/program-profilaktyki-raka-szyjki-macicy (access: 03.08.2020).

29. Jankowska P, Kikolska M, Kwiatkowska M, Kochman D, Głowacka M. The level of knowledge on cervical cancer among women. Innowacje Piel Nauk Zdr. 2017; 1: 22-46. 